Jurnal Kependudukan Indonesia | Vol. 14 No. 2 Desember 2019| 199-212

JURNAL KEPENDUDUKAN INDONESIA

p-ISSN : 1907-2902 (Print)

e-ISSN : 2502-8537 (Online)

\title{
PERAN PERHIMPUNAN PELAJAR INDONESIA (PPI) DALAM UPAYA PERLINDUNGAN TENAGA KERJA INDONESIA DI MALAYSIA
}

\section{(THE ROLE OF THE INDONESIAN STUDENT ASSOCIATION (PPI) IN THE EFFORT OF PROTECTION OF THE INDONESIAN LABOUR IN MALAYSIA)}

\author{
Rahmat Saleh, Dian Wahyu Utami, Irin Oktafiani \\ Pusat Penelitian Kependudukan, Lembaga Ilmu Pengetahuan Indonesia
}

Korespondensi penulis: rahmat.saleh@lipi.go.id

\begin{abstract}
International migration is usually motivated by economic reasons. However, many people also migrate overseas to continue studies in higher-level education. This paper analyses the role of Indonesian students abroad, especially those who are members of the Indonesian Student Association (PPI) in protecting Indonesian workers (TKI). The research is focused on PPI in the country with the highest number of Indonesian migrant workers, namely Malaysia. This study applied a qualitative approach to collect primary and secondary data. Primary data was collected through interviews, and secondary data was gained through literature review. The research shows that PPI, as an agent of change, has a role in protecting migrant workers. The PPI has various kinds of contributions such as expressing ideas and discourses to protect international migrant workers, becoming a mediator (in solving conflicts involving the workers), facilitating shelter, providing repatriation assistance, legal assistance and advocacy, as well as economic empowerment and education activities for migrant workers and their families.
\end{abstract}

Keywords: international student migration, Indonesia overseas students' association, Indonesian international migrant workers' protection

\begin{abstract}
Abstrak
Alasan ekonomi merupakan salah satu faktor yang menyebabkan seseorang bermigrasi ke luar negeri. Namun ada juga yang bermigrasi untuk melanjutkan studi ke jenjang yang lebih tinggi. Artikel ini mengkaji peran pelajar Indonesia di luar negeri, khususnya yang tergabung di dalam Perhimpunan Pelajar Indonesia (PPI) dalam upaya perlindungan terhadap tenaga kerja Indonesia (TKI). Penelitian difokuskan pada PPI di negara yang memiliki jumlah TKI paling banyak yaitu Malaysia. Penelitian ini menggunakan pendekatan kualitatif. Data primer dikumpulkan melalui wawancara dan data sekunder melalui telaah pustaka. Berdasarkan penelitian ini diketahui bahwa PPI memiliki peran dalam upaya perlindungan TKI. Peran tersebut diwujudkan melalui berbagai kontribusinya seperti sumbangan ide/gagasan, diskursus, menjadi mediator, memfasilitasi rumah singgah, bantuan pemulangan, bantuan dan pendampingan hukum (advokasi), serta kegiatan pemberdayaan ekonomi maupun pendidikan bagi TKI dan keluarganya.
\end{abstract}

Kata Kunci: migrasi pelajar internasional, Perhimpunan Pelajar Indonesia (PPI), perlindungan tenaga kerja Indonesia 
Jurnal Kependudukan Indonesia | Vol. 14, No. 2, Desember 2019 | 199-212

\section{PENDAHULUAN}

Mobilitas penduduk, internal dan internasional merupakan fenomena kependudukan yang terjadi sepanjang masa. Pada konteks regional, akhir-akhir ini terjadi peningkatan arus migrasi internasional, seperti di kawasan Asia Tenggara (ASEAN). Hal tersebut dipengaruhi oleh adanya krisis ekonomi di negara asal migran. Secara teoritik, tingginya beban ekonomi per kapita yang tidak sebanding dengan tingkat pendapatan yang rendah di negara asal menyebabkan migran bersikap rasional memilih ke luar menuju negara yang kondisi ekonominya relatif lebih baik. Ditambah pula, perkembangan teknologi informasi dan komunikasi serta mudahnya akses transportasi juga turut mendorong terjadinya arus migrasi internasional yang semakin masif (Chan \& Zhang, 1998).

Menurut Testaverde dkk. (2017), pada 20 tahun terakhir (dari tahun 1995 hingga 2015) terjadi tren peningkatan migran pencari kerja di ASEAN. Negara-negara seperti Malaysia, Singapura, dan Thailand menjadi pusat (hub) tujuan migrasi di kawasan tersebut, dengan menerima sekitar 6,5 juta migran atau $96 \%$ dari total pekerja migran di ASEAN. Data ini memperlihatkan bahwa alasan ekonomi menjadi faktor utama yang menyebabkan terjadinya migrasi internasional di kawasan tersebut.

Indonesia menjadi negara penyumbang utama dalam peningkatan migran pencari kerja ke luar negeri. BNP2TKI (Badan Nasional Penempatan dan Perlindungan Tenaga Kerja Indonesia) mencatat sebanyak 2,5 juta tenaga kerja Indonesia (TKI) bekerja di luar negeri pada rentang tahun 2011-2016 ${ }^{1}$. Jumlah TKI di luar negeri diperkirakan lebih besar dari angka tersebut, mengingat masih banyak di antara mereka yang pergi ke luar negeri tanpa dokumen dan tidak tercatat secara resmi di BNP2TKI. Jumlah mereka tersebar di Asia Tenggara dan Asia Timur (Malaysia, Singapura, Hong Kong, Taiwan), serta Timur Tengah (Saudi Arabia, Kuwait, dan Uni Emirat Arab). Di antara negara-negara tersebut, Malaysia menjadi negara tujuan paling favorit bagi TKI.

Selain karena alasan ekonomi, migrasi internasional juga didorong oleh faktor lain, misalnya untuk tujuan

1

http://www.bnp2tki.go.id/uploads/statistik/images/data_0802-2017_111324_Data- pendidikan, terutama melanjutkan studi ke jenjang yang lebih tinggi. Namun, cukup sulit mendapatkan data statistik resmi tentang jumlah dan sebaran warga negara Indonesia yang sedang belajar di luar negeri. Hal ini dikarenakan studi mengenai migrasi untuk tujuan pendidikan masih jarang dilakukan di Indonesia (Malamassam dkk., 2017).

Para pelajar Indonesia di luar negeri, idealnya tidak hanya semata-mata melakukan kegiatan belajar. Mereka diharapkan juga peka terhadap isu-isu sosial kemanusiaan yang terjadi di sekitar mereka, khususnya yang menyangkut warga negara Indonesia yang rentan terhadap diskriminasi dan eksploitasi. Di negara-negara penempatan TKI, salah satu isu yang perlu mendapat perhatian adalah perlindungan terhadap mereka.

TKI merupakan kelompok yang rentan terhadap berbagai pelanggaran dan diskriminasi. Sejumlah studi mengenai migrasi tenaga kerja internasional, di antaranya IOM (2010) dan Romdiati (2015), menyebutkan bahwa dalam melaksanakan pekerjaannya di luar negeri, TKI seringkali mengalami tindak kekerasan /penyiksaan yang dalam beberapa kasus mengakibatkan kematian. Menurut data BNP2TKI, yang juga dikutip oleh Migrant Care (2018), dalam rentang tahun 2012-2017 jumlah TKI yang meninggal - dan dipulangkan ke tanah air - mencapai 1.267 kasus. Malaysia menjadi negara dengan jumlah kasus kematian TKI terbesar setiap tahun, baik di kawasan Asia Pasifik mapun di tingkat global. Oleh karena itu, sudah semestinya TKI mendapatkan perlindungan dari negara melalui berbagai upaya, termasuk dari warga negara Indonesia yang sedang menuntut ilmu di negara penempatan TKI.

Asosiasi warga negara Indonesia yang berada di luar negeri, seperti para pelajar Indonesia yang mengorganisasikan dirinya di dalam Perhimpunan Pelajar Indonesia (PPI) diharapkan menjadi "elemen lain perwakilan negara Indonesia" di luar negeri. Secara kapabilitas organisasi, PPI memiliki tanggung jawab moril sebagai agent of change. Pergerakan PPI, dalam perjalanan sejarahnya, juga kemudian diperluas pada aktivitas pada isu-isu sosial kemanusian, seperti perlindungan TKI. Tulisan ini bertujuan untuk

P2TKI_tahun_2011-2016.pdf 
menggambarkan peran PPI dalam upaya perlindungan TKI di era pasca reformasi.

Penelitian terhadap asosiasi dalam kaitannya dengan perlindungan TKI sudah banyak dilakukan, namun kajian terbatas mengenai peran lembaga swadaya masyarakat (LSM) atau non-governmental organisation (NGO) (Wahyono, 2007; Raharto \& Noveria, 2012; Sumardiani, 2014; Wahyudi \& Jusoh, 2016; Andayani, tt). Masih sangat sedikit kajian yang melihat peran asosiasi pelajar dalam perlindungan TKI. Peran asosiasi pelajar menjadi penting karena jumlah pelajar Indonesia di luar negeri semakin meningkat tiap tahun dan memiliki posisi yang strategis dalam menjalin relasi dengan TKI, perwakilan negara Indonesia, dan pemerintah negara setempat.

\section{METODOLOGI}

Penelitian ini menggunakan pendekatan kualitatif untuk mengumpulkan data primer dan sekunder. Pengumpulan data primer dilakukan melalui wawancara dengan informan yang menguasai informasi yaitu pelajar Indonesia yang sedang atau pernah bergabung dalam organisasi PPI serta tinggal di luar negeri atau di Indonesia.

Informan yang dipilih adalah mereka yang pernah atau sedang menjabat sebagai pengurus PPI. Wawancara dilakukan terhadap tiga informan (dua orang dari PPI Malaysia dan satu orang PPI Dunia). Data sekunder dikumpulkan melalui telaah pustaka berupa buku, artikel, jurnal, prosiding, dan hasil konferensi/seminar/diskusi. Penelusuran informasi/data dilakukan melalui internet.

\section{MIGRASI PELAJAR KE LUAR NEGERI: BRAIN DRAIN DAN BRAIN GAIN}

Dari beberapa kelompok migran internasional (buruh migran, keluarga migran, dan pengungsi), migrasi pelajar ke luar negeri (international students) adalah kelompok yang berkembang pesat sejak awal abad ke21. Meskipun demikian, pada lingkup studi migrasi internasional, penelitian mengenai international students masih jarang dilakukan. Kajian terkait international students yang sudah dilakukan masih berfokus pada pengidentifikasian alasan-alasan yang memotivasi mereka pergi ke luar negeri untuk mendapatkan gelar pendidikan yang lebih tinggi dan pengalaman belajar serta strategi bertahan hidup selama di luar negeri (Riaño \& Piguet, 2016).

Baru belakangan ini, beberapa studi memberikan perhatian cukup serius terhadap kelompok international students sebagai sumber daya yang potensial. Selain karena jumlahnya yang semakin meningkat, international students yang berpendidikan tinggi merupakan agent of change yang dimiliki suatu negara. Hal ini karena kelompok ini memperoleh bekal ilmu pengetahuan dan teknologi dari negara maju yang dapat membantu proses pembangunan di negara asal (Haris, 2005; Wahyuni, 2013). International students tidak hanya berpindah secara fisik tetapi juga menciptakan ruang-ruang baru dalam pengetahuan akademis dan mengkonfigurasi konstitusi serta kekuasaan secara global (Raghuram, 2013; Madge dkk., 2014).

Dalam praktiknya, kegiatan international students tidak semata-mata melakukan kegiatan belajar, tetapi juga terlibat dalam aktivitas gerakan sosial politik. Tingginya mobilitas kelompok ini, memudahkan mereka dalam berinteraksi dengan sesama pelajar, akademisi, praktisi, aktivis, pejabat, dan berbagai pihak lain, tidak hanya dalam konteks antarnegara di tingkat regional tetapi juga internasional. Keadaan ini menyebabkan kelompok ini memiliki lebih banyak kesempatan untuk mempengaruhi kelompok migran lainnya, misalnya dalam hal mendorong perubahan atau penolakan terhadap suatu regulasi.

Pada literatur migrasi dan pembangunan di tahun 1970an seringkali international students memunculkan kekhawatiran akan fenomena brain drain atau kebocoran sumber daya manusia andal (high skill) bagi negara asal. Awalnya mereka pergi meninggalkan negaranya untuk tujuan belajar, kemudian setelah lulus - dengan alasan mereka masing-masing - memilih berkarir menjadi profesional di luar negeri.

Istilah brain drain ini popular sekaligus menakutkan terutama bagi negara-negara berkembang mengingat sumber daya manusia (SDM) yang berkualitas memilih berkarir di luar negeri, padahal mereka sangat diperlukan untuk membangun negaranya sendiri. Pada saat yang bersamaan, di lain sisi juga muncul situasi yang mendukung brain drain tersebut yakni brain gain. Brain gain adalah usaha dari suatu negara (khususnya negara-negara maju) dengan berbagai cara untuk 
Jurnal Kependudukan Indonesia | Vol. 14, No. 2, Desember 2019 | 199-212

mendapatkan para emigran dari berbagai negara, tentunya mereka yang memiliki pengetahuan (knowledge) dan pengalaman (best practices) profesional guna membantu pembangunan negara tersebut (Aditama, 2015).

Fenomena brain drain - brain gain ini berkembang hingga akhir tahun 1990-an. Saat ini kekhawatiran akan fenomena tersebut tidak berlaku lagi, karena sekarang mereka adalah pelaku aktif brain circulation atau sirkulasi sumber daya manusia andal (Rizvi, 2005). Menurut Mahroum (1999), brain circulation membawa keuntungan secara mutual dua arah baik negara asal maupun negara penerima.

Sebagai pelaku aktif brain circulation, international students kini semakin menyadari pentingnya berkontribusi untuk memajukan negaranya masingmasing. Kesadaran tersebut juga didukung oleh keberadaan jaringan global, yaitu konektivitas SDM berkualitas dari negara dan ras manapun untuk menciptakan 'ruang kolaborasi' agar mereka dapat melakukan aktivitas yang lebih baik, dengan berbekal keahlian dan pengalamannya masing-masing.

Lebih lanjut, international students memiliki keterbukaan berpikir dan kemampuan berkomunikasi yang baik sehingga mereka umumnya aktif berjejaring dengan berbagai komunitas untuk melakukan kegiatan bersama. Sebagai contoh, biasanya mereka melakukan diskusi untuk mengasah pemikiran kritis atau sekadar pertukaran pengetahuan seni budaya. Tidak kalah penting, seringkali mereka mengembangkan kolaborasi riset atau melakukan kajian dengan tujuan mencari solusi atas permasalahan yang dihadapi sesama migran di luar negeri, termasuk persoalan tenaga kerja migran.

\section{PPI DARI PRA-KEMERDEKAAN HINGGA PASCA REFORMASI}

Para pelajar Indonesia di luar negeri memiliki sejarah penting sebagai salah satu kontributor bagi pembangunan Indonesia (Elias, 2013). Dalam catatan sejarahnya, kesadaran akan kontribusi tersebut telah muncul sejak masa pra-kemerdekaan. Mereka mengorganisasikan diri ke dalam sebuah wadah pergerakan pelajar Indonesia, yang kemudian dikenal dengan sebutan Perhimpunan Pelajar Indonesia (PPI). Oleh karena itu, peran PPI dalam kapasitasnya sebagai agen perubahan tidak bisa dikesampingkan.

Kontribusi PPI tercermin dari respons organisasi ini terhadap berbagai isu yang menyangkut tanah air. Hal ini bisa dilihat dalam sejarah periodisasi PPI yang terbagi dalam lima fase, yakni Pra-Kemerdekaan, Orde Lama, Orde Baru, Transisi Orde Baru, dan Era Reformasi, seperti yang terlihat pada Tabel 1.

Tabel 1. Periodisasi PPI

\begin{tabular}{|lll|}
\hline \multicolumn{1}{|c}{ Fase } & \multicolumn{1}{c|}{ Isu-isu Strategis } & \multicolumn{1}{c|}{ Keterangan } \\
\hline Pra Kemerdekaan & - Kalangan priyayi bisa bertahan di & - Inisiasi oleh anak para raja \\
(Zaman kolonial) & tengah laju modernisasi dan & kaya dan bangsawan yang \\
& utamanya bisa setara dengan & sekolah di Belanda. \\
& orang Eropa. & - Tahun 1908 terbentuk \\
& - Kesadaran gagasan kolektif untuk & Indische Vereeniging atau \\
& memperjuangkan kemerdekaan & Perhimpunan Hindia sebagai \\
& bangsa Indonesia. & wadah pergerakan bagi pelajar \\
& & dan mahasiswa Hindia di \\
& & Belanda. Organisasi inilah \\
& & yang menjadi cikal-bakal \\
& & Perhimpunan Pelajar \\
& Indonesia (PPI). \\
\hline
\end{tabular}


Lanjutan Tabel 1.

\begin{tabular}{|c|c|c|}
\hline Fase & Isu-isu Strategis & Keterangan \\
\hline $\begin{array}{l}\text { Orde Baru } \\
(1966-1990)\end{array}$ & $\begin{array}{l}\text { - Demokratisasi, menentang rezim } \\
\text { yang otoritarian. } \\
\text { - Gerakan pelajar pro demokrasi } \\
\text { Indonesia. }\end{array}$ & $\begin{array}{l}\text { - Sejak pemerintahan Orde Baru } \\
\text { berkuasa, kiprah sosial politik } \\
\text { PPI meredup, kegiatan PPI } \\
\text { dialokasikan untuk acara-acara } \\
\text { kesenian dan kebudayaan. } \\
\text { - Beberapa aktivis PPI Belanda } \\
\text { dan Amsterdam bekerja sama } \\
\text { dengan PPI Berlin } \\
\text { menerbitkan "Berita } \\
\text { Indonesia" mengkritisi } \\
\text { Pemerintahan Soeharto. } \\
\text { Akibatnya mereka dipersulit } \\
\text { saat akan pulang maupun } \\
\text { berkegiatan di Indonesia. } \\
\text { - PPI Australia juga tampil } \\
\text { cukup berani mendukung } \\
\text { demokratisasi. }\end{array}$ \\
\hline $\begin{array}{l}\text { Transisi Orde Baru } \\
(1990-2000)\end{array}$ & $\begin{array}{l}\text { - Demokratisasi. } \\
\text { - Pemerintahan yang bersih dari } \\
\text { KKN. }\end{array}$ & $\begin{array}{l}\text { - Adanya kebebasan berserikat, } \\
\text { berkumpul dan berpendapat } \\
\text { baik secara lisan maupun } \\
\text { tulisan bagi setiap warga } \\
\text { negara. } \\
\text { - Mulai berkembangnya } \\
\text { kemajuan teknologi (internet). }\end{array}$ \\
\hline $\begin{array}{l}\text { Era Reformasi } \\
\text { (2001 - sekarang) }\end{array}$ & $\begin{array}{l}\text { - Penegakan Hukum \& hak azasi } \\
\text { manusia (HAM). } \\
\text { - Politik, Ekonomi, Sosial, Budaya, } \\
\text { dan berbagai isu persoalan } \\
\text { lainnya. }\end{array}$ & $\begin{array}{l}\text { - Keberadaan PPI semakin } \\
\text { menunjukkan eksistensinya. } \\
\text { - Semangat giving back } \\
\text { (berkontribusi) bagi kemajuan } \\
\text { Indonesia. } \\
\text { - Tahun } 2007 \text { terbentuk PPI } \\
\text { Dunia yakni Dewan Presidium } \\
\text { yang mengakomodasi dan } \\
\text { mengkoordinasikan potensi } \\
\text { PPI di berbagai negara. }\end{array}$ \\
\hline
\end{tabular}

Pasca reformasi, PPI semakin berkembang menjadi organisasi yang besar. Selain karena bertambahnya anggota dengan beragam strata pendidikan (S1, S2, S3, dan Post Doktoral) dan universitas, berbagai isu yang dibahas dalam skala nasional ataupun internasional. Karena itu, di tahun 2007 dibentuklah PPI Dunia sebagai jaringan global yang mengkoordinasikan PPI di berbagai negara. Jumlah anggota PPI Dunia yang terdata sampai dengan tahun 2018 sebanyak lebih dari 86.000 pelajar, tersebar di 55 negara. Di luar jumlah tersebut, diperkirakan masih ada ribuan pelajar Indonesia yang tersebar di sejumlah negara. PPI Dunia terbagi ke dalam tiga kawasan yaitu Asia-Oceania,
Amerika-Eropa, dan Timur Tengah-Afrika. Pembagian wilayah per kawasan ini bertujuan agar terjalin sinergi isu gerakan dan kegiatan PPI sekawasan. Karena di negara yang berdekatan dalam satu kawasan terdapat kecenderungan isu-isu persoalan yang relatif sama.

Pada Gambar 1 yang menyajikan jumlah dan sebaran anggota PPI Dunia terlihat bahwa secara organisasional cakupan PPI Dunia bergerak dari tingkat antarkawasan hingga antarnegara. PPI di tingkat negara (PPI negara) sebagai sebuah organisasi mempunyai struktur berbentuk cabang atau dikenal sebagai Chapter Movement. Sebagai contoh, PPI cabang Universiti Kebangsaan Malaysia atau chapter UKM merupakan 
Jurnal Kependudukan Indonesia | Vol. 14, No. 2, Desember 2019 | 199-212

organisasi yang mempunyai basis massa berdasarkan komunitas daerah atau etnis Indonesia yang kuliah di UKM. Komunitas daerah atau etnis ini di dalam PPI
Cabang dikenal dengan sebutan Paguyuban, Ikatan Keluarga, Persatuan Masyarakat atau Persatuan Pelajar Daerah (Ramza dkk., 2016).

Gambar 1. Jumlah dan sebaran PPI Dunia

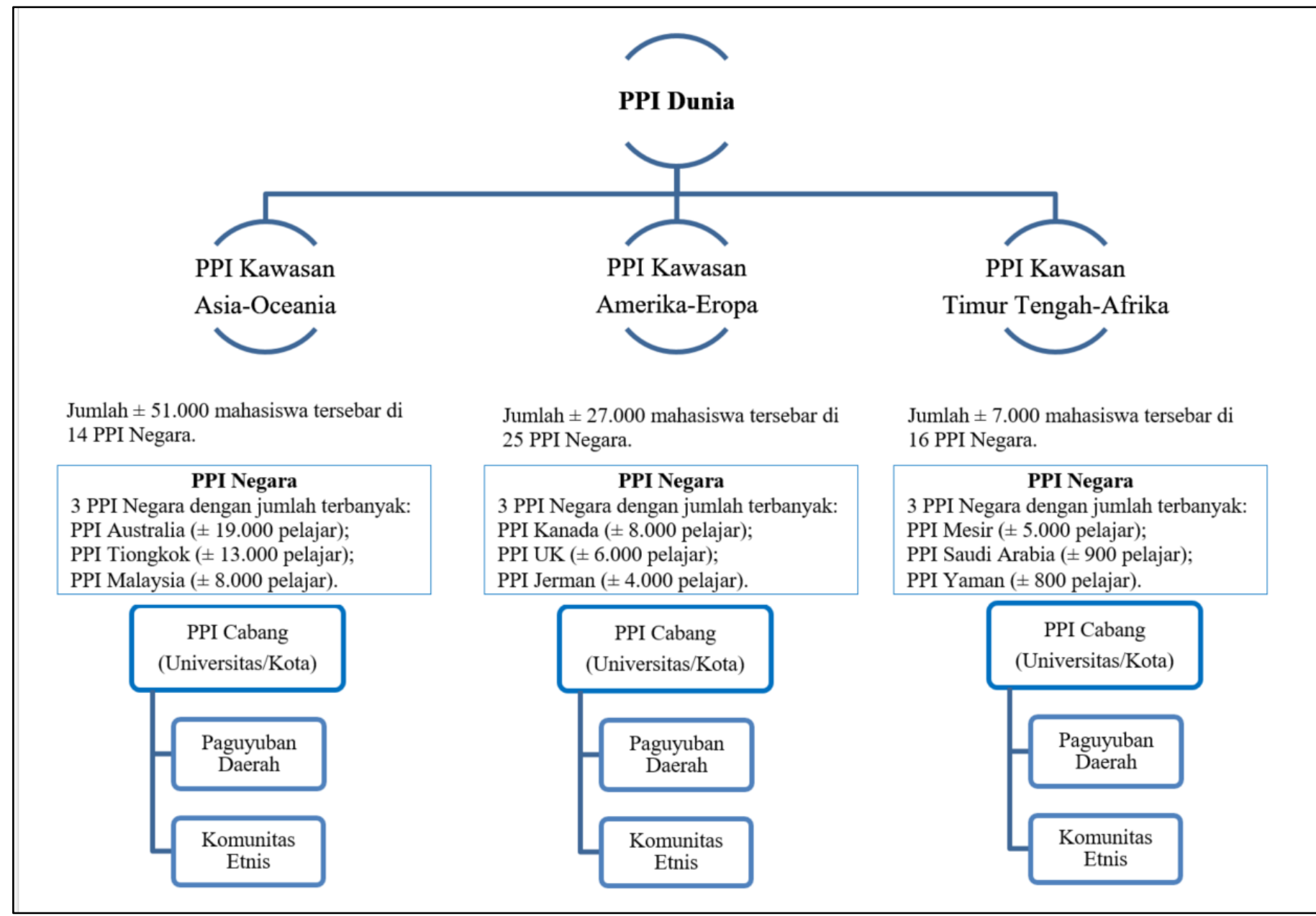

Sumber: Diolah dari Ramza dkk., (2016); http://ppidunia.org/; database statistic PPI Dunia 2018; data primer (wawancara dengan informan PUM di Jakarta);

\section{AKTIVISME PPI DI ERA PASCA-REFORMASI}

Di era pasca-reformasi ini, Indonesia mengalami berbagai perubahan fundamental, khususnya dalam sistem pendidikan. Salah satunya ialah akses yang terbuka luas bagi setiap anak bangsa untuk mengenyam pendidikan tinggi hingga ke luar negeri. Hal ini ditandai dengan adanya sejumlah program beasiswa yang secara rutin ditawarkan oleh pemerintah kepada masyarakat untuk melanjutkan studi ke luar negeri. Melalui program beasiswa ini ada harapan besar dari pemerintah untuk menghasilkan SDM yang berkualitas dengan intelektualitas tinggi yang akan berkontribusi bagi kemajuan tanah air.
Biaya studi mayoritas anggota PPI yang sedang menempuh pendidikan tinggi ditanggung oleh lembaga donor beasiswa, baik nasional (pemerintah) maupun internasional (non-pemerintah). Oleh karena itu, PPI memiliki tanggung jawab moral yang lebih baik di bidang akademik maupun non-akademik. PPI semakin menyadari hakikat pelajar Indonesia di luar negeri, tidak hanya untuk menuntut ilmu tetapi juga melakukan kegiatan-kegiatan yang bermanfaat, terutama untuk merespon isu-isu terkini yang dihadapi bangsa dan negara Indonesia. Upaya tersebut dapat dilakukan baik dalam bentuk lisan, tulisan, maupun aksi nyata yang dituangkan ke dalam landasan dan program kerja organisasi PPI. Hal ini disebutkan pada Anggaran Dasar (AD) PPI Dunia bahwa salah satu tujuan organisasi 
ialah meningkatkan kontribusi dan peran PPI di berbagai negara dalam berbagai kegiatan untuk mendukung pembangunan Indonesia yang berkelanjutan. Berdasar garis koordinasi secara organisasi, ruang lingkup kegiatan PPI di berbagai negara sejalan dengan PPI Dunia, atau dengan kata lain
PPI di berbagai negara menjadi representasi PPI Dunia. Dalam AD juga disebutkan ruang lingkup kegiatan PPI, diantaranya sosial-kemanusiaan, budaya, dan pendidikan. Tabel 2 menyajikan beberapa kegiatan PPI di era pasca reformasi.

Tabel 2. Gambaran umum kegiatan PPI

\begin{tabular}{|c|c|c|c|}
\hline \multirow[b]{2}{*}{ PPI } & \multicolumn{3}{|c|}{ Kegiatan } \\
\hline & $\begin{array}{c}\text { Sosial } \\
\text { (kemanusiaan/komunitas) }\end{array}$ & Budaya & Pendidikan \\
\hline $\begin{array}{c}\text { PPI } \\
\text { Dunia }\end{array}$ & $\begin{array}{l}\text { 'Community Development' } \\
\text { - Kegiatan dalam rangka } \\
\text { melestarikan tenun dan } \\
\text { tradisi penenun, terutama } \\
\text { untuk meningkatkan } \\
\text { kesejahteraan komunitas } \\
\text { penenun tradisional di } \\
\text { NTT. }\end{array}$ & $\begin{array}{l}\text { 'Be Indonesian for } \\
\text { a Day' } \\
\text { - Kegiatan untuk } \\
\text { membangun citra } \\
\text { positif Indonesia di } \\
\text { mata dunia, melalui } \\
\text { pengenalan seni } \\
\text { dan budaya serta } \\
\text { kuliner nusantara. }\end{array}$ & $\begin{array}{l}\text { 'What Brings You Back Home' } \\
\text { - Motivasi dari para profesional yang } \\
\text { pernah belajar di luar negeri mengenai } \\
\text { alasan mereka kembali untuk } \\
\text { Indonesia. } \\
\text { Realisasi kegiatan: "Bantu Guru } \\
\text { Melihat Dunia (BGMD)" \& "Ruang } \\
\text { Berbagi Ilmu (RUBI)" yang bertujuan } \\
\text { untuk meningkatan kualitas pendidikan } \\
\text { di Indonesia. }\end{array}$ \\
\hline $\begin{array}{c}\text { PPI } \\
\text { Negara }\end{array}$ & $\begin{array}{l}\text { PPI Yordania: } \\
\text { Memberikan bantuan } \\
\text { bagi pengungsi Palestina } \\
\text { dan Suriah } \\
\\
\text { PPI Tiongkok, PPI } \\
\text { Malaysia, dan beberapa } \\
\text { PPI negara lainnya: } \\
\text { Menggalang dana sosial } \\
\text { bagi korban bencana } \\
\text { gempa bumi di Lombok } \\
\text { Indonesia. }\end{array}$ & $\begin{array}{l}\text { PPMI Mesir: } \\
\quad \text { Atmosphere of } \\
\quad \text { Indonesia } 2018 \\
\\
\text { > PPI di Aligarh } \\
\quad \text { India: "Harmony } \\
\quad \text { in Cultural } \\
\quad \text { Diversity" } \\
\\
\text { Kegiatan di Mesir } \\
\text { dan India ini } \\
\text { merupakan ajang } \\
\text { untuk } \\
\text { mempromosikan } \\
\text { kesenian dan } \\
\text { kebudayaan } \\
\text { Indonesia ke } \\
\text { seluruh penjuru } \\
\text { dunia. }\end{array}$ & $\begin{array}{l}\text { PPI Thailand (Permitha): } \\
\text { \#Gerakan1000SepatuSekolahPermitha } \\
\text { Kegiatan Permitha ini dalam rangka } \\
\text { meningkatkan pendidikan anak } \\
\text { Indonesia. } \\
\text { PPI Taiwan: } \\
\text { Universitas Terbuka Taiwan (UTT) } \\
\text { dan Pusat Kegiatan Belajar } \\
\text { Masyarakat (PKBM) } \\
\text { PPI Taiwan ini menyelenggarakan } \\
\text { pendidikan tinggi dan kesetaraan bagi } \\
\text { TKI dan anaknya. }\end{array}$ \\
\hline
\end{tabular}

Sumber: Diolah dari Rusdiana \& Zaim (tt); http://ppidunia.org/; panel pendidikan, sosial dan budaya Sarasehan Nasional PPI Dunia, 10 Maret 2018; laporan pertanggungjawaban PPI Dunia 2015-2018; data primer (wawancara dengan informasi II di Jakarta)

Tabel 2 menggambarkan kontribusi PPI bagi pembangunan Indonesia, melalui kegiatan sosial, budaya, dan pendidikan. Kesibukan studi di luar negeri ternyata tidak membuat para pelajar Indonesia lupa akan kondisi bangsanya. Pada konteks era pasca reformasi, kepedulian para pelajar Indonesia di luar negeri berlangsung bukan baru-baru ini saja. Rusdiana (2017) menyebutkan bahwa PPI Amerika Serikat (Permias), PPI Australia, PPI Belanda, PPI Jerman, PPI Inggris, PPI Jepang, PPI India, dan PPI Qatar 
mengumpulkan dana sosial untuk korban tsunami di Aceh tahun 2006 silam. Berdasarkan informasi pada Tabel 2 terlihat bahwa kepedulian PPI tidak hanya bagi tanah air, tetapi juga terhadap bangsa-bangsa di dunia (seperti yang telah dilakukan oleh PPI Yordania).

\section{KONTRIBUSI PPI MALAYSIA DALAM UPAYA PERLINDUNGAN TKI}

Terselenggaranya simposium PPI di Kawasan AsiaOseania pada tahun 2018 merupakan bentuk softadvocacy PPI atas persoalan perdagangan manusia dan pekerja migran (human trafficking and migrant workers), termasuk kasus TKI. Kegiatan tersebut menegaskan komitmen PPI di berbagai negara untuk terus membantu hal-hal terkait kasus TKI, sesuai dengan kemampuan dan kapasitasnya. PPI menyadari bahwa TKI secara tidak langsung turut meningkatkan harkat martabat bangsa serta negara dan sebagai anak bangsa berhak diapresiasi, dilindungi, serta ditingkatkan kemampuannya. Kegiatan simposium yang berlangsung di Thailand ini menghasilkan empat poin rekomendasi, yaitu:

1. Mendorong pemerintah Indonesia untuk membuat kesepakatan dengan agensi yang menjadi penyalur tenaga kerja dan menyarankan setiap perwakilan atau instansi terkait untuk melakukan pemantauan langsung terhadap agen yang menyalurkan pekerja migran Indonesia.

2. Mengusulkan pemerintah Indonesia untuk memperkuat pengamanan perbatasan, dengan cara penambahan jumlah aparat keamaan, penggunaan teknologi, dan melakukan peninjauan kembali terhadap jalur-jalur yang berpotensi tinggi untuk keluar masuknya imigran ilegal.

3. Memproduksi buku panduan untuk calon $\mathrm{PMI}^{2}$ (Pekerja Migran Indonesia) yang dihimpun berdasarkan informasi dan pengalaman dari berbagai pemangku kepentingan di masing-masing negara penempatan.

4. Menghimpun informasi dari PPI negara setempat mengenai sistem pencegahan dan penanganan imigran ilegal yang dapat menjadi referensi dalam

2 Berdasar UU No. 18 Tahun 2017 Tentang Pelindungan Pekerja Migran Indonesia yang disahkan menjelang akhir tahun 2017, istilah TKI berubah menjadi PMI (pekerja migran Indonesia). Artikel ini masih menggunakan istilah upaya penyelesaian permasalahan pekerja imigran ilegal Indonesia.

Rekomendasi tersebut di atas merupakan kotribusi PPI dalam upaya perlindungan terhadap TKI, khususnya di Kawasan Asia-Oseania. Seperti diketahui selama ini perlindungan bagi TKI masih sangat minim. Padahal, TKI baik yang terdokumentasi maupun tidak terdokumentasi, menopang perekonomian negara. Jika merujuk pada data BNP2TKI yang didasarkan pada laporan Bank Indonesia, jumlah remitansi TKI dari tahun 2011-2016 tercatat lebih dari 6 milyar dolar per tahun. Artinya, jumlah remitasi tersebut adalah yang secara resmi dikirim oleh para TKI melalui jasa perbankan atau yang tercatat di perbankan. Jumlah tersebut belum termasuk remitansi jalur nonperbankan, misalnya uang yang dibawa langsung oleh TKI atau yang dititipkan melaui teman-teman sesama TKI yang pulang ke Indonesia.

Minimnya perlindungan bagi TKI yang bekerja di luar negeri menyebabkan mereka rentan mengalami kekerasan, pelecehan seksual, tereksploitasi perkerjaan, perdagangan orang, dan berbagai bentuk tindak kekerasan lainnya. Studi yang dilakukan oleh Raharto dan Noveria (2012) memperlihatkan bahwa kerentanan pada TKI, khususnya perempuan, berupa pelecehan dan eksploitasi terutama karena sifat pekerjaannya dan juga sebagai akibat diskriminasi jender. Selanjutnya, Wahyudi dan Jusoh (2016) menyebutkan beberapa bentuk diskriminasi, stigma dan stereotype yang dialami TKI di Malaysia, di antaranya adalah overwork atau melebihi jam kerja yang disepakati, tidak ada hak cuti/libur/ijin, diskriminasi upah, kontrol agen yang terlalu kuat, tidak adanya reunifikasi (menikah, keluarga, hamil), tidak adanya asuransi kesehatan, dan pembatasan media informasi.

Persatuan Pelajar Indonesia se-Malaysia (PPIM) sebagai satu-satunya organisasi pelajar Indonesia terbesar di Malaysia sudah berperan dalam membantu TKI di kawasan Asia-Oseania, khususnya di Malaysia untuk memperoleh perlindungan melalui berbagai kegiatan keorganisasiannya. Secara kelembagaan PPIM tampak potensial dengan sumber daya yang dimilikinya. Hingga tahun 2018, anggota

TKI, karena saat penelitian ini dilakukan di pertengahan tahun 2018 istilah PMI belum tersosialisasikan dengan baik. Dengan demikian, istilah TKI masih dipakai guna memudahkan penelusuran data dan informasi. 
PPIM berjumlah sekitar 8.000 mahasiswa dari berbagai strata akademik dengan pengurus aktif mencapai kurang lebih 80 orang, serta memiliki 33 cabang yang tersebar di tanah Semenanjung, Sabah, dan Sarawak.
Dalam struktur PPIM terdapat divisi hukum \& advokasi serta sosial kesejahteraan masyarakat, yang kegiatannya sedikit-banyak berinteraksi dengan TKI. Berikut beberapa kegiatan PPIM yang terkait dengan upaya perlindungan TKI.

Tabel 3. Kegiatan PPIM terkait upaya perlindungan TKI

\begin{tabular}{|c|c|c|}
\hline No. & Deskripsi Kegiatan & Keterangan \\
\hline 1 & $\begin{array}{l}\text { PPIM berpartisipasi menjadi relawan pengajar atau } \\
\text { pengurus di Pusat Kegiatan Belajar Masyarakat } \\
(\mathrm{PKBM}) \text {. }\end{array}$ & $\begin{array}{l}\text { PKBM adalah fasilitas pendidikan non- } \\
\text { formal bagi masyarakat Indonesia } \\
\text { (terutama bagi TKI dan anak-anaknya) } \\
\text { di Kuala Lumpur. Kegiatan belajar- } \\
\text { mengajar ini setara dengan program } \\
\text { paket A, B, dan C. }\end{array}$ \\
\hline 2 & $\begin{array}{l}\text { PPIM bekerjasama dengan Dompet Dhuafa dalam } \\
\text { rangka meningkatkan kualitas pendidikan dan } \\
\text { pemberdayaan masyarakat Indonesia (TKI dan anak- } \\
\text { anaknya) di Malaysia, terutama di wilayah-wilayah } \\
\text { terpencil atau perbatasan Indonesia-Malaysia. }\end{array}$ & $\begin{array}{l}\text { Membuat sekolah non-formal dan } \\
\text { pelatihan-pelatihan (pengelolaan } \\
\text { keuangan, menjahit, komputer, } \\
\text { memasak, dll). }\end{array}$ \\
\hline 3 & $\begin{array}{l}\text { PPIM bekerjasama dengan KBRI: } \\
\text { (a) Mengupayakan Surat Perjalanan Laksana } \\
\text { Paspor (SPLP) dan mencarikan sponsorship } \\
\text { guna pemulangan para TKI yang bermasalah. } \\
\text { (b) Program pemutihan paspor bagi lebih dari } \\
600.000 \text { TKI tidak berdokumen. }\end{array}$ & $\begin{array}{l}\text { TKI dikenai denda yang sangat mahal } \\
\text { oleh imigrasi Malaysia. } \\
\text { PPIM menyadari bahwa status tidak } \\
\text { berdokumen menjadi penyebab TKI } \\
\text { tidak terlindungi. }\end{array}$ \\
\hline 4 & $\begin{array}{l}\text { Pernyataan Sikap PPIM: } \\
\text { (a) Merespon atas terjadinya segala kasus yang } \\
\text { diperbuat oleh warga Malaysia terhadap TKI. } \\
\text { (b) Atas insiden penembakan TKI oleh aparat } \\
\text { polisi Malaysia, terlebih ada indikasi } \\
\text { pengambilan organ tubuh pada korban. } \\
\text { Aksi pernyataan sikap ini merupakan bagian dari } \\
\text { embrio 'TKI Help \& Care' PPI Dunia. }\end{array}$ & $\begin{array}{l}\text { PPIM mendesak pemerintah Malaysia } \\
\text { agar penegakan hukum di Malaysia } \\
\text { berdasar pada prinsip keadilan dan } \\
\text { kemanusiaan. } \\
\text { PPIM meminta pemerintah Indonesia } \\
\text { (KBRI di Malaysia) untuk melayangkan } \\
\text { 'nota protes' kepada pemerintah } \\
\text { Malaysia. }\end{array}$ \\
\hline 5 & $\begin{array}{l}\text { Sumbangan tulisan PPIM; } \\
\text { (a) "The Relationship Dynamics of Malaysia and } \\
\text { Indonesia: Indonesian Migrant Workers" } \\
\text { dimuat di website PPIM. } \\
\text { (b) "Melindungi Para Pejuang Devisa di } \\
\text { Malaysia" dimuat di Harian Kompas. }\end{array}$ & $\begin{array}{l}\text { PPIM menyuarakan pentingnya } \\
\text { perlindungan TKI agar kehidupan TKI } \\
\text { sejahtera. } \\
\text { PPIM meminta pemerintah Indonesia } \\
\text { untuk memastikan perlindungan semua } \\
\text { TKI terjamin sesuai UU No. } 18 \text { Tahun } \\
2017 \text {. }\end{array}$ \\
\hline
\end{tabular}

Sumber: Diolah dari Hasanah (2015); http://ppidunia.org/; http://www.ppi-malaysia.org; Webinar 'Lawan hukum trafficking dan lindungi para migrant (jilid II), PPI TV; notulensi Simposium Kawasan Asia Oseania 12 Mei 2018; laporan pertanggungjawaban PPI Dunia 2015-2018; data primer (wawancara dengan informan ZE \& DA di Jakarta) 
Kegiatan-kegiatan pada Tabel 3 menunjukkan bahwa PPIM merupakan kelompok yang potensial untuk membantu pemerintah, terutama dalam kasus-kasus TKI di luar negeri. PPIM di sini jelas memiliki peran strategis sebagai agen perubahan, yang dalam operasionalnya berkolaborasi dengan instansi pemerintah dan organisasi swasta-nirlaba (LSM/NGO). Oleh karena itu, dapat dikatakan bahwa kegiatankegiatan PPIM dalam upaya perlindungan TKI adalah bentuk gerakan intelektual yang berbasis pada isu-isu sosial (advokasi hak-hak TKI).

Kegiatan PPI di berbagai negara termasuk di Malaysia, mulanya sekadar ajang silaturahmi dan sinergi gagasan politik bagi seluruh pelajar Indonesia di luar negeri. Akan tetapi, dalam perjalanannya PPI semakin menunjukkan kontribusinya pada isu-isu dan persoalan social kemanusian. Kondisi ini antara lain dilatarbelakangi oleh keprihatinan PPI pada problematika TKI yang tak kunjung reda. Menurut salah satu informan (PUM), munculnya sikap peduli di kalangan aktivis PPI terhadap TKI dilandasi rasa persaudaraan sesama anak bangsa dan program pengembangan diri, diskusi, aksi sosial merupakan sarana kontribusi intelektual. Selain itu, beberapa program dilakukan oleh PPI sesuai dengan kemampuan dan keahliannya masing-masing seperti program Community Learning Center (CLC) untk memberikan pendidikan kepada anak-anak para TKI di Malaysia. Hal ini sangat penting dilakukan mengingat anak-anak TKI sebagai warga negara Indonesia juga memiliki hakhak mendasar (HAM) seperti hak atas pendidikan dan perlindungan hukum. Secara konstitusional pemerintah berkewajiban untuk memastikan terjaminnya pemenuhan hak-hak tersebut sesuai dengan peraturan perundang-undangan.

Raharto dan Noveria (2012) menjelaskan bahwa pemenuhan hak-hak TKI oleh lembaga-lembaga (pemerintah dan swasta) mencakup tiga tahap, yaitu (i) pra-kerja/pra-pemberangkatan (recruitment dan training); (ii) selama bekerja (di tempat kerja); dan (iii) purna kerja (kembali ke tanah air). Wujud kontribusi PPI pada aspek perlindungan TKI secara kelembagaan tampak pada kegiatan penyuluhan, pelatihan, dan pendampingan hukum (advokasi). Kegiatan ini dibuat untuk membantu TKI meningkatkan kompetensinya agar lebih layak menjalani hidup di luar negeri. Kontribusi PPI dalam upaya perlindungan TKI patut diapresiasi dan terus didukung sebab kontribusi mereka baik melalui keorganisasian maupun perseorangan semakin terlihat dan bergaung di kancah nasional ataupun internasional. Kondisi ini terlihat dari isu-isu strategis yang menjadi bahasan dalam kongres internal PPI pada tahun 2017-2018, seperti terlihat pada Tabel 4.

Tabel 4. Isu-isu Strategis PPI

\begin{tabular}{|c|l|l|}
\hline No. & \multicolumn{1}{|c|}{ Isu Strategis } & \multicolumn{1}{|c|}{ Keterangan } \\
\hline 1 & $\begin{array}{l}\text { Perlindungan dan } \\
\text { kesejahteraan pekerja } \\
\text { migran }\end{array}$ & $\begin{array}{l}\text { Pendidikan, } \\
\text { pelatihan, advokasi } \\
\text { bagi TKI dan anak- } \\
\text { anaknya }\end{array}$ \\
\hline 2 & Peduli bencana tanah air & $\begin{array}{l}\text { Bantuan bagi para } \\
\text { korban bencana } \\
\text { alam di tanah air }\end{array}$ \\
\hline 3 & $\begin{array}{l}\text { Perkembangan ekonomi } \\
\text { politik Kawasan }\end{array}$ & $\begin{array}{l}\text { Indonesia di tingkat } \\
\text { Asia \& Oseania }\end{array}$ \\
\hline 4 & $\begin{array}{l}\text { Promosi pariwisata, } \\
\text { kesenian, dan } \\
\text { kebudayaan Indonesia }\end{array}$ & $\begin{array}{l}\text { Upaya } \\
\text { meningkatkan citra } \\
\text { positif Indonesia }\end{array}$ \\
\hline 5 & $\begin{array}{l}\text { Pemerataan } \\
\text { pembangunan yang } \\
\text { berkeadilan }\end{array}$ & $\begin{array}{l}\text { Terutama di daerah } \\
\text { 3T (tertinggal, } \\
\text { terpencil, terluar) }\end{array}$ \\
\hline
\end{tabular}

Sumber: Diolah dari http://ppidunia.org/; laporan pertanggungjawaban PPI Dunia 2015-2018; data primer (wawancara dengan informan PUM di Jakarta)

Penelitian ini menemukan bahwa gerakan intelektual PPI terlihat masih kurang optimal. Temuan penelitian ini sejalan dengan hasil kajian yang dilakukan oleh Hasanah (2015) yang menyatakan bahwa PPI masih kurang dalam melakukan kampanye dan promosi terkait pekerja migran Indonesia, padahal sebenarnya mereka memiliki kemampuan untuk menjembatani antara para TKI, pemerintah, serta Lembaga Bantuan Hukum (LBH).

Kenyataan bahwa pada tahun 2018, isu perlindungan TKI menjadi tema utama yang dibahas pada Simposium Internasional PPI Kawasan Asia-Oseania. Namun demikian, beberapa pengurus PPI yang diwawancarai mengakui bahwa kontribusi organisasi ini pada aspek perlindungan TKI belum optimal. PPI melihat bahwa secara umum TKI membutuhkan perlindungan, namun tidak dalam bentuk solusi yang seragam. Selama ini kontribusi PPI dalam upaya perlindungan bagi TKI dilakukan dengan beragam cara, seperti: (i) sumbangan ide/gagasan melalui forum diskusi, seminar, audiensi, pernyataan sikap, press release; (ii) pemikiran/diskursus melalui tulisan opini, makalah, 
jurnal, pemberitaan di media internasioanl/nasional, video di media sosial; (iii) bantuan dan pendampingan hukum (atas kasus pelanggaran hukum); (iv) menjadi mediator/negosiator (atas terjadinya perselisihan gaji/pungutan); (v) menjadi fasilitator antara pemerintah, pengusaha (agen), TKI, majikan, dan pihak-pihak terkait; (vi) bantuan dana sosial (massive charity); dan (vii) fasilitasi rumah singgah.

Lebih lanjut, beberapa pengurus PPI juga menyadari bahwa mereka tidak bisa bekerja sendirian dalam upaya perlindungan TKI. Kolaborasi diperlukan untuk meningkatkan upaya perlindungan hukum bagi TKI agar lebih optimal. Oleh karena itu, PPI memerlukan kolaborasi dengan berbagai pihak, baik pemerintah maupun swasta, diantaranya akademisi, praktisi sosial, pemerintah (Atase Pendidikan dan Kebudayaan KBRI, kementerian, dan lembaga terkait), DPR, dan direksi perusahaan. Sebagai contoh, kolaborasi yang dibangun antara PPIM dengan KBRI Kuala Lumpur Malaysia, dimana PPIM dipercaya sebagai fasilitator dalam advokasi TKI.

Berdasarkan analisis hasil wawancara juga diperoleh gambaran tentang penting dan strategisnya posisi PPI dalam menyuarakan nasib TKI. PPI secara kelembagaan telah menempatkan dirinya untuk membantu TKI memperoleh hak-haknya sebagai pekerja migran selama bekerja di luar negeri. Sebagai pelaku aktif brain circulation, kelompok pelajar ini semakin sadar akan tanggung jawab moralnya yaitu berkontribusi untuk memajukan bangsa dan negaranya. Dalam konteks penelitian ini, bisa dipahami bahwa pada era pasca reformasi, peran PPI dalam upaya perlindungan TKI dapat dilakukan melalui berbagai kontribusi kegiatannya yang berpihak kepada kepentingan TKI.

\section{KESIMPULAN}

Secara historis, sejak awal berdirinya PPI hingga era reformasi terlihat bahwa para pelajar Indonesia di luar negeri menaruh perhatian besar pada berbagai isu dan persoalan sosial-politik. Seiring perkembangan zaman, di era pasca reformasi mereka juga menaruh perhatian pada berbagai isu sosial kemanusiaan. Penelitian ini membuktikan bahwa PPI sebagai agent of change memiliki peran dalam upaya perlindungan terhadap TKI. Peran tersebut diwujudkan melalui berbagai kontribusinya seperti sumbangan ide/gagasan, diskursus, menjadi mediator, memfasilitasi rumah singgah (shelter), bantuan pemulangan (repatriation), bantuan dan pendampingan hukum (advokasi), serta kegiatan pemberdayaan ekonomi maupun pendidikan bagi TKI dan keluarganya agar mereka lebih sejahtera dan berdaya.

PPI yang berada di negara penempatan TKI, seperti di Malaysia, merupakan kelompok intelektual yang memiliki potensi dan posisi strategis dalam mengkampanyekan isu perlindungan TKI. Peran tersebut terutama dalam hal pemberian informasi serta menjadi jembatan komunikasi antara TKI dan perwakilan Indonesia serta pihak (pemerintah) Malaysia. Tingginya mobilitas kelompok ini memudahkan mereka dalam berinteraksi dan mempengaruhi stakeholders tidak hanya dalam konteks antarnegara di tingkat regional tetapi juga internasional. Oleh karena itu, diharapkan kegiatan-kegiatan PPI tidak hanya yang bersifat seremonial, tetapi juga manifestasi tanggung jawab moral yang membawa nama baik bangsa di tingkat global.

Perlindungan TKI sejatinya menjadi tanggung jawab utama pemerintah Indonesia. Namun, keterbatasan SDM perwakilan pemerintah Indonesia di luar negeri (baik di kedutaan besar maupun konsuler) menjadi alasan klasik atas lambannya memberikan perlindungan terhadap TKI. Penelitian ini merekomendasikan kepada pemerintah Indonesia agar melibatkan PPI melalui skema "saluran diplomatik" tersendiri sehingga perannya dalam upaya perlindungan terhadap TKI bisa lebih optimal dan diakui secara internasional. 


\section{DAFTAR PUSTAKA}

Aditama, I. G. K. (2015). Dampak globalisasi bagi Indonesia: Brain drain atau brain gain? https://fois.or.id/dampak-dampak-globalisasibagi-indonesia-brain-drain-atau-brain-gain$4 c 4 a 64394 b c 2$

Andayani, F. (tanpa tahun). Peran International Organization for Migration (IOM) dalam melindungi tenaga kerja Indonesia di Malaysia tahun 2013-2015. https://media.neliti.com/media/ publications/125016-ID-none.pdf

Chan, K. W., \& Zhang, Li. (1998). The Hukou system and rural-urban migration in China: Processes and changes. The China Quarterly, 160, 818-855. https://www.jstor.org/stable/656045

Elias, R. A. (2013). Invisible agent in Taiwan-Indonesia cooperation. http://fgumail.fgu.edu.tw/ cseas 2013/1-2-2.pdf

Haris, A. (2001). Migrasi internasional, jaminan perlindungan, dan tantangan ekonomi global. Populasi, 12(1), 3-20. https://doi.org/10.22146/ jp. 12272

Hasanah, T. (2015). Potential social capital of Indonesian immigrant in Malaysia: A preliminary research. Procedia - Social and Behavioral Sciences, $\quad 211(25), \quad 383-389$. https://doi.org/10.1016/j.sbspro.2015.11.050

International Organization for Migration [IOM]. (2010). Migrasi tenaga kerja dari Indonesia: Gambaran umum migrasi tenaga kerja Indonesia di beberapa negara tujuan di Asia dan Timur Tengah.

https://www.iom.int/jahia/webdav/shared/shared/ mainsite/published_docs/Final-LM-Report-

Bahasa-Indonesia.pdf

Madge, C., Raghuram, P., \& Noxolo, P. (2014). Conceptualizing international education: From international student to international study. Progress in Human Geography, 39(6), 1-21. https://doi.org/10.1177/0309132514526442

Mahroum, S. (1999). Highly skilled globetrotters: The international migration of human capital. http://citeseerx.ist.psu.edu/viewdoc/download?doi $=10 \cdot 1 \cdot 1.474 .6372 \&$ rep $=$ rep $1 \&$ type $=p d f$

Malamassam, M. A., Romdiati, H., Noveria, M., Setiawan, B. (2017). Mobilitas penduduk Indonesia dalam situasi global. Pustaka Sinar Harapan \& Pusat Penelitian Kependudukan LIPI.

Migrant Care. (2018). Sepanjang tahun 2017, 62 pekerja migran asal NTT meninggal di Malaysia. http://www.migrantcare.net/2018/02/sepanjangtahun-2017-62-pekerja-migran-asal-nttmeninggal-di-malaysia/

Raghuram, P. (2012). Theorising the spaces of student migration. Population, Space and Place, 19(2), 138-154. https://doi.org/10.1002/psp.1747

Raharto, A., \& Noveria, M. (2012). Advocacy groups for Indonesian women migrant workers' protection. Jurnal Kependudukan Indonesia, 7(1), 1-17. https://doi.org/10.14203/jki.v7i1.80

Ramza, H., Kubro, S., Habibi, M. R., Yordan, A., Maulana, T., Januardi, A. M. R., Pawinanto, R. E., Nasution, E., Trimasidy, A., \& Islami, I. (2016). Pembangunan visi dan misi Persatuan Pelajar Indonesia (PPI-UKM) tahun 2014 - $2015 \mathrm{di}$ Universiti Kebangsaan Malaysia, Selangor. Fikiran Masyarakat, 4(1), 32-41. http://www.kemalapublisher.com/index.php/fm/ar ticle/view/145

Riaño, Y. \& Piguet, E. (2016). International student migration: An annotated review of literature. Dalam B. Wharf (Ed.), Oxford bibliographies in geography (hal. 1-24). Oxford University Press. https://doi.org/10.1093/OBO/97801998740020141

Rizvi, F. (2005). International education and the production of cosmopolitan identities. http://hdl.handle.net/2142/3516

Romdiati, H. (2015). Globalisasi migrasi dan peran diaspora: Suatu kajian pustaka. Jurnal Kependudukan Indonesia, 10(2), 89-100. https://doi.org/10.14203/jki.v10i2.69

Rusdiana, Y. T. (2017). Peranan perhimpunan pelajarpelajar Indonesia dalam upaya mencapai kemerdekaan Republik Indonesia. Jurnal Sriwijaya Historia, 1(1), 42-55. https://jurnal.umpalembang.ac.id/jsriwijaya/article/view/673

Rusdiana, D. \& Saidi, Z. (tanpa tahun). Diaspora giving: An agent of change in Asia Pacific communities?

https://www.globalacademymnd.org/research/dias pora-giving-an-agent-of-change-in-asia-pacific/

Sumardiani, F. (2014). Peran serikat buruh migran Indonesia dalam melindungi hak tenaga kerja Indonesia di luar negeri. Pandecta, 9(2), 257-272. https://doi.org/10.15294/pandecta.v9i2.3579

Syahid, C. N. (2015). Mobilitas mahasiswa Indonesia di Belanda. Jurnal Kajian Wilayah, 6(1). 85-92. https://doi.org/10.14203/jkw.v6i1.71 
Testaverde, M., Moroz, H., Hollweg, C. H., \& Schmillen, A. (2017). Migrasi untuk mencari peluang: Mengatasi rintangan terhadap mobilitas tenaga kerja di Asia Tenggara. https://openknowledge.worldbank.org/bitstream/h andle/10986/28342/211106ovIndonesian.pdf?seq uence $=3 \&$ is Allowed $=y$

Wahyono, S. (2007). The problems of Indonesian migrant workers' rights protection in Malaysia. Jurnal Kependudukan Indonesia, 2(1), 27-44. https://doi.org/10.14203/jki.v2i1.139
Wahyudi, R. \& Jusoh, H. (2016). Encouraging access to justice for Indonesian migrant workers in Malaysia: The need of engaging legal aid organizations in ASEAN. Scientific Journal of PPI-UKM, 3(3), 143-151, https://doi.org/ 10.21752/sjppi-ukm/ses/a09092016

Wahyuni, D. (2013). Migrasi internasional dan pembangunan. Kajian, 18(4), 305-321. https://jurnal.dpr.go.id/index.php/kajian/article/vi ew/500

Widodo, Y. (2017). Media diaspora pelajar Indonesia: Eksistensi, peran, dan spirit keIndonesiaan. Jurnal Ilmu Komunikasi, 14(1), 93-110. https://doi.org/10.24002/jik.v14i1.974 
Jurnal Kependudukan Indonesia | Vol. 14, No. 2, Desember 2019|199-212 